\title{
Frontalis Transfer and Closed Silicone Rod Frontalis Suspension
}

\section{Yong Jig Lee, \\ David Dae Hwan Park}

Department of Plastic and Reconstructive Surgery, Catholic University of Daegu School of Medicine, Daegu, Korea
No potential conflict of interest relevant to this article was reported.
Background Improvements in the degree of marginal reflex distance $1\left(M R D_{1}\right)$ were compared before and after use of the frontalis transfer (FT) method and closed silicone rod frontalis suspension surgery (SS) for severe blepharoptosis under general or local anesthesia with or without minimal sedation.

Methods We reviewed the medical records and photographs of 76 patients who had visited our institute between 2006 and 2013 because of severe blepharoptosis with poor levator function and treated by the same senior doctor.

Results In total, 104 eyes (63 patients) were included after applying exclusion criteria; 71 eyes (44 patients) were corrected using FT, and 33 eyes (19 patients) were corrected using the frontalis sling method with a silicone rod. Among the general FT, local FT, general SS, and local SS groups, the mean preoperative MRD ${ }_{1}$ was not significantly different. Postoperative MRD, was highest in the local FT group.

Conclusions Both $\mathrm{FT}$ and $\mathrm{SS}$ positively increased $M R D_{1}$, regardless of the anesthesia used; however, the change in $\mathrm{MRD}_{1}$ of the general SS group was the lowest $(1.11 \pm 0.848 \mathrm{~mm})$. Further, general FT, local FT, and local SS groups had an approximate $2 \mathrm{~mm}$ or greater increase in the differences between postoperative and preoperative $M R D_{1}$. Specifically, the local FT group had a definite positive correlation with postoperative MRD.

Keywords Blepharoptosis, Data interpretation statistical, Eyelids, Silicones

\section{INTRODUCTION}

In severe blepharoptosis, surgical options can usually be divided depending upon the severity and extent of levator muscle function. In cases of poor levator muscle function, surgery with contraction of the frontalis is needed directly via the muscle itself or indirectly via an artificial material between the frontalis muscle and the tarsal plate. The frontalis sling technique has been considered the main

Received: Dec 25, 2015 Revised: Feb 10, 2016 Accepted: Feb 15, 2016 Correspondence: David Dae Hwan Park Department of Plastic and Reconstructive Surgery, Catholic University of Daegu School of Medcine, 2F, Raphael Building, Daegu Catholic University Hospital, 33 Duryugonwonro 17-gil, Nam-gu, Daegu 42472, Korea. E-mail: dhpark@cu.ac.kr

Copyright @ 2016 The Korean Society for Aesthetic Plastic Surgery.

This is an Open Access article distributed under the terms of the Creative Commons Attribution Non-Commercial License (http://creativecommons.org/licenses/by-nc/3.0/) which permits unrestricted non-commercial use, distribution, and reproduction in any medium, provided the original work is properly cited. www.e-aaps.org procedure to treat patients with severe eyelid ptosis for decades [16]. Blepharoptosis correction under local anesthesia via frontalis transfer (local FT) can be an effective, but aggressive treatment [7]. However, if the patient is young or afraid of undergoing surgery, then surgery can be performed under general anesthesia (general FT). Silicone rod suspension surgery, a less invasive but effective treatment option, could be also performed under either general (general SS) or local anesthesia (local SS) [8,9].

The intraoperative eyelid level was adjusted until the eyelid margin covered $1.5 \mathrm{~mm}$ below the superior limbus of the cornea. Because the same surgeon performed all the procedures examined in this study, the effectiveness in correcting severe blepharoptosis was examined to assess whether the two operative options could be substituted for each other. In addition, the authors compare the effectiveness of the surgical options under both local and general anesthesia. 


\section{METHODS}

We retrospectively compared the effectiveness of these surgical options in a non-randomized study. In the present study, we reviewed the medical records and photographs of 76 patients who had visited our clinic between 2006 and 2013 because of severe blepharoptosis and in whom a single senior doctor had performed the surgeries. Marginal reflex distance $1\left(\mathrm{MRD}_{1}\right)$ was measured as the vertical distance from the corneal light reflex during primary gaze to the upper eyelid margin. The levator function is the difference in height of the upper lid margin between the highest and lowest points of vision after the surgeon presses the patients' eyebrow to block frontalis muscle function [10]. A postoperative result was considered sufficiently symmetrical if the calculated difference between the postoperative $\mathrm{MRD}_{1}\left(\mathrm{PostMRD}_{1}\right)$ values of both eyes was $1 \mathrm{~mm}$ or less [11].

\section{Surgical procedure}

Silicone rod frontalis suspension surgeries were performed under general (general SS) or local (local SS) anesthesia with minimal sedation using the pentagon modified technique [12]. One BD Visitec $^{\mathrm{TM}}$ 20-gauge, 2-1/2 inch stainless steel, double straight needle ( 0.8 $\mathrm{mm} \times 40 \mathrm{~cm}$ solid silicone rod; Becton Dickinson and Company, Franklin Lakes, NJ, USA) was used. The eyelid skin was marked on the medial and lateral parts, and two stab incisions were made on the upper eyelid. Temporal and nasal horizontal incisions were made on the fold line of the upper eyelid, extending within $3 \mathrm{~mm}$ of the lateral and medial corneal limbus. In addition, the lateral, medial, and forehead incisions were made above the eyebrow. Lateral and medial eyebrow incisions were made approximately $3 \mathrm{~mm}$ above the orbital rim vertical to the lateral and medial canthal lines toward the temporal and nasal regions, respectively (Fig. 1). In addition, a $5-\mathrm{mm}$ forehead skin incision was made $7 \mathrm{~mm}$ above the central eyebrow around the orbital rim centrally. A lid guard was inserted for ocular protection. At first, 1:100,000 epinephrine mixed with $1 \%$ lidocaine was administered. After the incision and dissec-
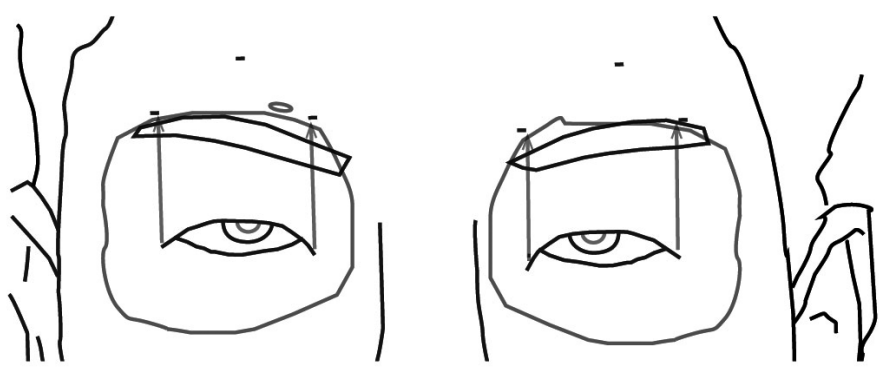

Fig. 1. Illustration of skin stab incision sites above eyebrows. Lateral and medial eyebrow incisions were made approximately $3 \mathrm{~mm}$ above the orbital rim, vertical to the lateral and medial canthal lines toward the temporal and nasal regions, respectively. tion of the five incision windows, one end of the straight needle was passed from the lateral eyelid incision window to the medial brow incision between the eyelid skin and orbicularis oculi muscle. Moreover, both a silicone rod and the superior margin of the tarsal plate were tied and fixed together with 7-0 nylon at two points through the eyelid windows, just after withdrawing the silicone rod back along the needle track. That end of the needle was passed through the medial eyelid incision window to the medial brow incision, and the other end of the needle was directed through the lateral eyelid window to the lateral brow window. The eyelid level was adjusted until the eyelid margin was elevated to cover $1.5 \mathrm{~mm}$ below the superior limbus of the cornea. Finally, both ends of the needles were passed through the central forehead incision window. Both parts of the extracted silicone rods were passed through the additional silicone tube and secured with 6-0 nylon to prevent loosening of the knots, and located under the frontalis muscle of the forehead. The skin brow incisions were closed with 5-0 vicryl and 6-0 nylon, and the eyelid incisions were sutured using 7-0 nylon.

FTs were also performed under general (general FT) or local (local FT) anesthesia. Two incision lines were designed just below the ipsilateral eyebrow and eyelid fold line, and 1:100,000 epinephrine mixed with $1 \%$ lidocaine was then administered. After the brow incision was made using a beveling approach to avoid the hair follicle, the L-shaped frontalis muscle flap was elevated to avoid injury to the facial nerve. Then, via the eyelid incision, the tarsal plate was exposed, and a tunnel from the tarsal plate to the brow window between the skin and orbicularis oculi muscle was created. The harvested muscle flap was transposed and attached to the anterior border of the tarsal plate via a temporary PDS suture. The eyelid level was also adjusted until the eyelid margin was elevated to cover 1.5 $\mathrm{mm}$ below the superior limbus of the cornea. After the corrected target level was checked, two PDS sutures were used to maintain the frontalis muscle and tarsal plate. The brow and eyelid skin sutures were secured using 7-0 nylon after the insertion of silastic drainage [7].

\section{Statistical analysis}

Data analysis for $\mathrm{MRD}_{1}$ was performed using SPSS statistical software (version 16; SPSS Inc., Chicago, IL, USA). Data are expressed as the mean \pm standard deviation (SD). An independent sample ttest was used to compare preoperative $\mathrm{MRD}_{1}\left(\mathrm{PreMRD}_{1}\right)$, Post$M R D_{1}$, and differences between PostMRD ${ }_{1}$ and PreMRD ${ }_{1}$ (Dif$\mathrm{fMRD}_{1}$ ). PostMRD $\mathrm{D}_{1}$ in the study groups was compared using the independent sample $t$-test after assuming equal variances or the Mann-Whitney test without assuming equal variances. The correlations in several variables such as age, surgical options, type of anesthesia, PreMRD 1 , PostMRD $D_{1}$, and DiffMRD $D_{1}$ were analyzed. In addition, improvements in the degree of ptosis were defined as the difference between PostMRD ${ }_{1}$ and PreMRD $D_{1}$. A two-sided P-value less than 0.05 was considered statistically significant. 


\section{RESULTS}

\section{Patient characteristics}

In all, 76 patients who had visited our institute between 2006 and 2013 had severe, unilateral, or bilateral blepharoptosis and poor levator function. In all, 13 patients were excluded from the study because of Bells phenomenon ( 2 patients), previous surgical history (9 patients), and trauma ( 2 patients). Finally, 63 patients (104 eyes) with severe bilateral ( 41 patients, about $65 \%$ ) or severe unilateral (22 patients, about $35 \%$ ) ptosis were selected. In all, 44 patients (71 eyes) were treated using FT (age: $34.4 \pm 16.49$ years), and 19 patients (33 eyes) were corrected using silicone rod frontalis suspension surgery (age: $37.8 \pm 24.41$ years) under general or local anesthesia (Table 1). About $57 \%$ of patients were male.

\section{Statistical significance}

We examined the correlation between several variables examined in this study. The patient group that underwent general anesthesia had a strong correlation with general FT. The patient group that underwent a SS had a strong correlation with local SS. Older age was definitely correlated with the group of all patients receiving local anesthesia and with the local SS group, and had a weak correlation with DiffMRD $D_{1}$. Younger age was definitely correlated with the group of all patients under general anesthesia and with the local SS group, and had a weak correlation with PreMRD $D_{1}$ The group with a larger PreMRD 1 had a weak correlation with the group that underwent local FT and with PostMRD $\mathrm{D}_{1}$. The group with a smaller $\mathrm{PreMRD}_{1}$ had a strong correlation with $\mathrm{DiffMRD}_{1}$. There was no positive correlation between $\operatorname{PreMRD}_{1}$ and the group that underwent general SS. PostMRD $\mathrm{D}_{1}$ had a definite positive correlation with DiffMRD $_{1}$, the group undergoing FT, and with the local FT group.
PostMRD 1 had a weak positive correlation with PreMRD ${ }_{1}$ and the group under local anesthesia (Fig. 2).

The mean preoperative $\mathrm{MRD}_{1}$ among the four groups was not statistically significant with a P-value of 0.162 by the Kruskal-Wallis independent test. The mean postoperative $\mathrm{MRD}_{1}$ in the local FT group was the highest $(2.05 \pm 0.681 \mathrm{~mm})$, that of the general FT group was $1.78 \pm 0.647 \mathrm{~mm}$, that of the local SS group was $1.10 \pm$ $1.331 \mathrm{~mm}$, and that of the general SS group was the lowest $(0.70 \pm$ $0.706 \mathrm{~mm}$ ). The difference between PostMRD ${ }_{1}$ and PreMRD ${ }_{1}$ in the general FT group was $2.17 \pm 1.339 \mathrm{~mm}$, in the local FT group was $2.04 \pm 1.224 \mathrm{~mm}$, in the local SS group was $2.01 \pm 1.963 \mathrm{~mm}$, and in the general SS group was $1.11 \pm 0.848 \mathrm{~mm}$. The difference in $\mathrm{MRD}_{1}$ was $2 \mathrm{~mm}$ or greater in the general FT, local FT, and local SS groups, but not in the general SS group (Table 2 and 3). All surgical procedures resulted in a positive increase in the $\mathrm{MRD}_{1}$ value (Fig. 3).

\section{Surgical outcomes}

The percentage of patients with satisfaction with symmetry after surgery was as follows: $100 \%$ in the general FT group, $97.1 \%$ in the local FT group, $83.3 \%$ in the local SS group, and $53.8 \%$ in the general SS group. The general FT group had no early or late complications or revisional operations, the local FT group had five cases (9.4\%), the local SS group had three cases (13.6\%), and the general SS had one case (9.1\%) (Table 1 and 4 ).

\section{DISCUSSION}

In cases of poor levator function, the frontalis sling technique has been considered the main procedure for treating patients with severe blepharoptosis [13]. The typical method is to sling the upper eyelid tarsus with the frontalis muscle itself; there are many differ-

Table 1. Demographic information on the age and surgery undergone by the patient population

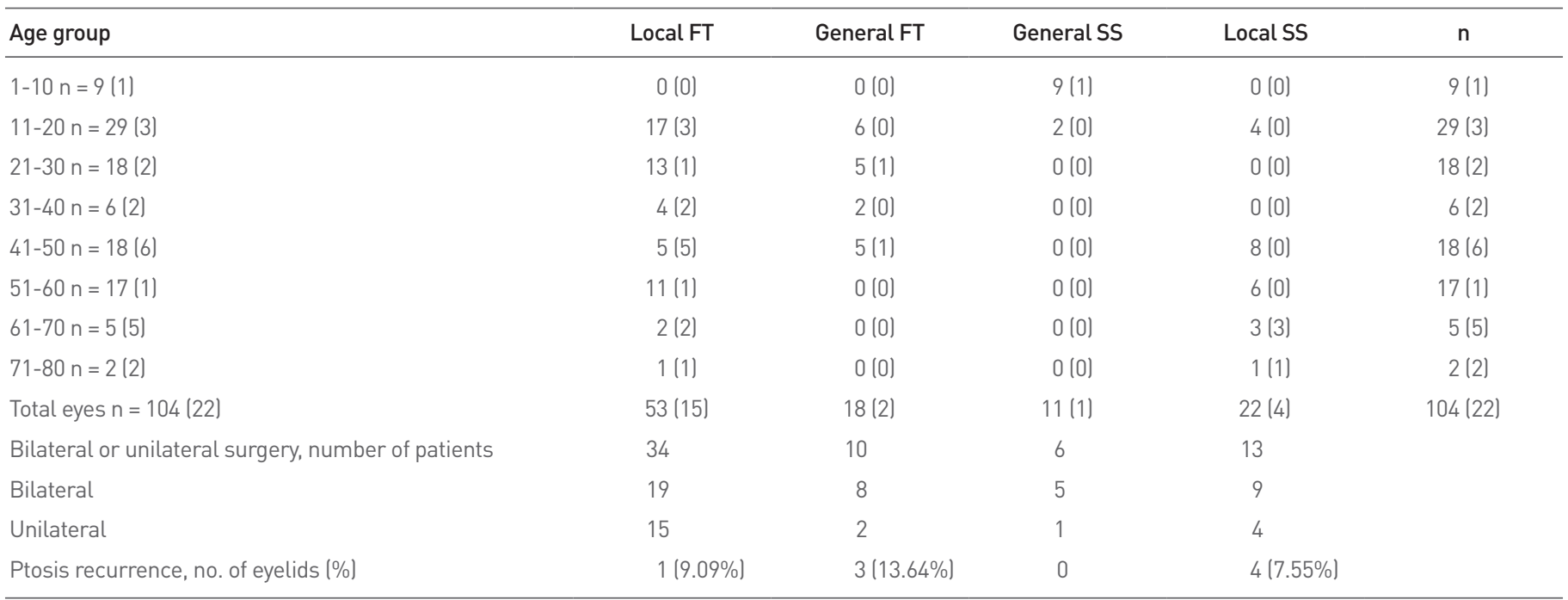

Local, under local anesthesia; General, under general anesthesia; FT, frontalis transfer; SS, silicone sling; n, count of affected eyes, (\#), count of unilateral ptosis. 


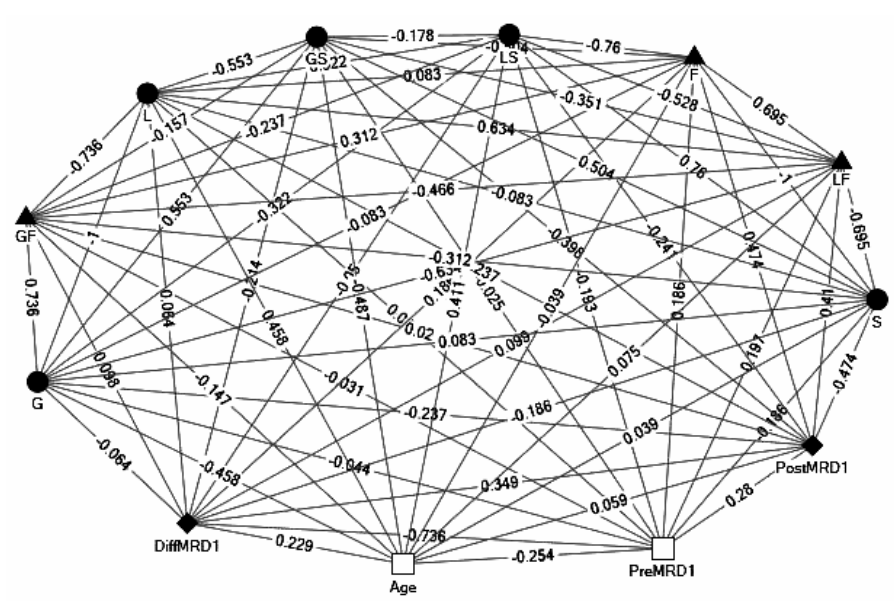

Created with NodeXL Pro (http://nodexl.codeplex.com) from the Social Media Research Foundation (http://www.smrfoundation.org)

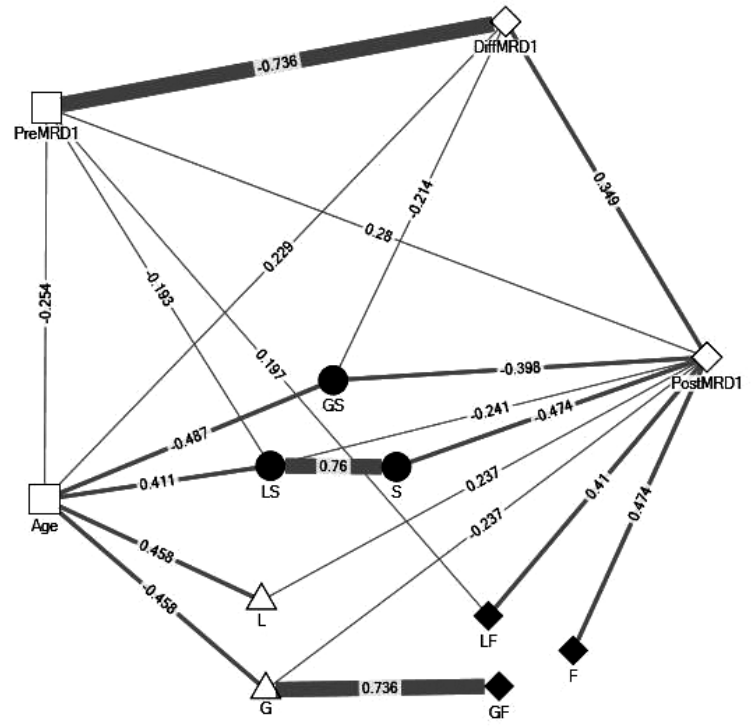

Created with NodeXL Pro (http://nodexl.codeplex.com) from the Social Media Research Foundation (http://www.smrfoundation.org)

Fig. 2. Illustration created by the NodeXL pro software program on statistical correlations of variables on this study. (A) Diagram shows all the variables and their correlation in this study. (B) Diagram shows the statistically significant variables and their correlations. A wider line means a strong correlation, and a narrow line means a weak correlation. Frontalis tranfer operation had correlationship with larger PostMRD, and silicone sling (SS) had correlationship with smaller PostMRD. There is no correlation if there is no line between the variable points. Frontalis transfer had no correlation with type of anesthesia with age. In the SS operation, older age had an obvious correlation with local anesthesia, and younger age had a definite correlation with general anesthesia. G, general anestheisa; L, local anesthesia; F, frontalis transfer; S, silicone sling; MRD1, marginal reflex distance 1 ; PreMRD1, preoperative MRD ; PostMRD, postoperative MRD 1 ; DiffMRD , the differecne between Post$M R D_{1}$ and PreMRD1.

Table 2. The mean value of each marginal reflex distance 1 in the study groups

\begin{tabular}{lccc}
\hline & $\begin{array}{c}\text { PreMRD }_{1} \\
\text { Mean } \pm \text { SD }(\mathrm{mm})\end{array}$ & $\begin{array}{c}\text { PostMRD }_{1} \\
\text { Mean } \pm \text { SD }(\mathrm{mm})\end{array}$ & $\begin{array}{c}\text { DiffMRD }_{1} \\
\text { Mean } \pm \text { SD }(\mathrm{mm})\end{array}$ \\
\hline Local FT & $0.01 \pm 1.391$ & $2.05 \pm 0.681$ & $2.04 \pm 1.224$ \\
General FT & $-0.39 \pm 1.195$ & $1.78 \pm 0.647$ & $2.17 \pm 1.339$ \\
General SS & $-0.41 \pm 1.281$ & $0.70 \pm 0.706$ & $1.11 \pm 0.848$ \\
Local SS & $-0.91 \pm 1.623$ & $1.10 \pm 1.331$ & $2.01 \pm 1.963$ \\
\hline
\end{tabular}

The difference of the mean PreMRD 1 among four groups (local FT, general FT, general SS, and local SS) was not statistically significant with a P-value of 0.162 by the Kruskal-Wallis independent test.

$\mathrm{FT}$, frontalis transfer; $S \mathrm{~S}$, silicone sling; $\mathrm{MRD}_{1}$, marginal reflex distance ${ }_{1}$ Pre-, preoperative; Post-, postoperative; DiffMRD 1 , PostMRD $1-$ PreMRD $_{1}$.

ent alternative methods such as levator resection, Müller-aponeurosis composite flap advancement, and the frontalis suspension procedure. The latter is commonly performed using bridge materials such as preserved fascia lata (PFL) or synthetic materials like polyester, polytetrafluoroethylene, nylon, polypropylene, and silicone rods, although there is no general agreement on which material is superior when compared to the others $[14,15]$. In the case of autologous materials, there have been concerns about donor site scarring. In the PFL group, later recurrence is known to be related to absorption of the fascia $[8,16]$. Fascia lata is not always a feasible option for all patients, as the patient needs to be at least 3 years old in order to have sufficient length to provide suitable fascia lata [17]. Some studies have recommended using silicone rods $[18,19]$. Therefore, we focused on increases in the $\mathrm{MRD}_{1}$ using these techniques in a retrospective, non-randomized study that compared FT and silicone rod frontalis suspension surgery under general or local anesthesia in our institution, including at least 6 months of follow up. If the patient had an early complication, details of the first postoperative $M R D_{1}$ was used instead of the postoperative $M R D_{1}$ of the repeat surgery after 6 months.

A lower PreMRD ${ }_{1}$ value indicates a greater severity of ptosis. In this study, the mean PreMRD $D_{1}$ of all 104 eyelids was $-0.34 \pm 1.371$ $\mathrm{mm}$; the PreMRD 1 values in the local FT group $(0.01 \pm 1.391 \mathrm{~mm})$, the general FT group $(-0.39 \pm 1.195 \mathrm{~mm})$, the local SS group $(-0.91$ $\pm 1.623 \mathrm{~mm})$ and general SS group $(-0.41 \pm 1.281 \mathrm{~mm})$ were not significantly different from one another. Based on this finding, we compared PostMRD $\mathrm{D}_{1}$ and $\mathrm{MRD}_{1}$ differences between the two procedures under general or local anesthesia.

To assess symmetry and determine whether the eyelid level was adjusted to a good position, intraoperative direct decisions can be more simply and reliably made under local anesthesia. Therefore, such direct prediction is believed to be more suitable to correct 
Table 3. Mean values with standard deviation of each marginal reflex distance

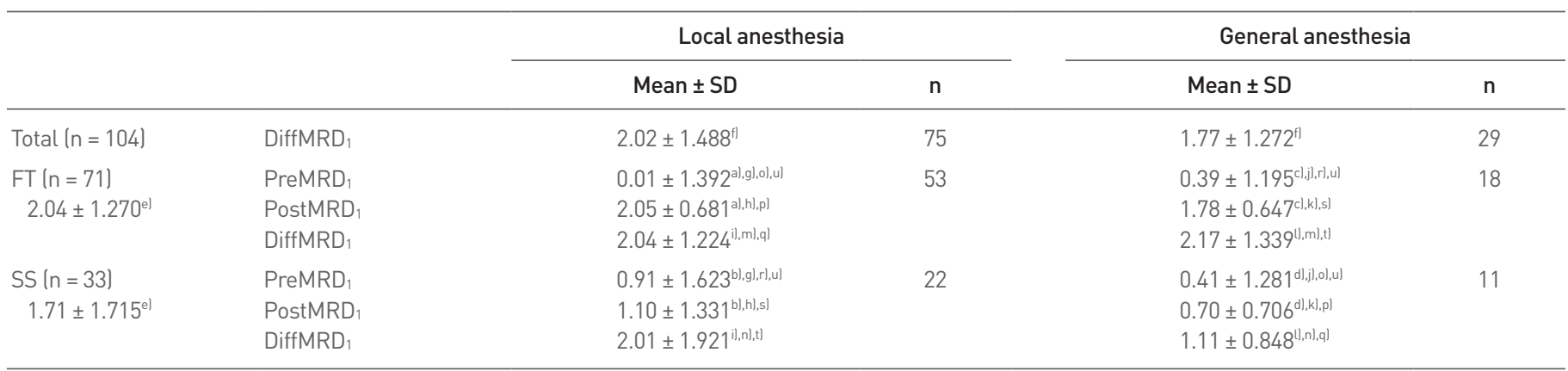

${ }^{a, b}$ The difference of the mean value between PreMRD 1 and PostMRD 1 was statistically significant in the FT procedure and the SS method under local anesthesia with P-value of ${ }^{a l} 0.000$ and ${ }^{b l} 0.000$, respectively, by the Wilcoxon test. ${ }^{c, d}$ The difference of the mean value between PreMRD 1 and PostMRD 1 was statistically significant in both the FT and the SS method under general anesthesia with P-value of ${ }^{\mathrm{cl}} 0.001$ and ${ }^{\mathrm{d}} 0.005$, respectively, by the Wilcoxon test. ${ }^{\text {el }}$ Regardless of the anesthesia, the difference of the mean value between the FT and the SS method in DiffMRD $\left(=\right.$ PostMRD $_{1}-$ PreMRD $\left._{1}\right)$ was not statistically significant with $P=0.078$ according to the Mann-Whitney test. ${ }^{\text {fl }}$ Regardless of the surgical method, the difference of the mean value between local anesthesia and general anesthesia in DiffMRD, was not statistically significant with $\mathrm{P}=0.514$ according to the Mann-Whitney test. Under local anesthesia, ${ }^{9}$ the difference of the mean value between the FT and the SS method in PreMRD 1 was statistically significant with $\mathrm{P}=0.026$ by an independent sample t-test. ${ }^{\text {h/ }}$ The difference of the mean value between the FT and the SS method in PostMRD, was also significant with $\mathrm{P}=0.000$ by the Mann-Whitney test. However, ilthe difference of the mean value between the FT and the SS method in DiffMRD, was not statistically significant with $\mathrm{P}=0.430$ by the Mann-Whitney test. Under general anesthesia, ${ }^{\mathrm{j}}$ the difference of the mean value between the FT and the SS method in PreMRD, was not statistically significant with $\mathrm{P}=1.000$ by the Mann-Whitney test. ${ }^{\mathrm{k}}$ However, the difference of the mean value between the FT and the SS method in PostMRD1 was statistically significant as $\mathrm{P}=0.001$ by the Mann-Whitney test. "The difference of the mean value between the FT and the SS method in DiffMRD 1 was significant statistically with $\mathrm{P}=0.015$ by independent sample t-test. ${ }^{\mathrm{m} / \mathrm{n})}$ The difference of the mean value of the DiffMRD, between the local and the general anesthesia was not statistically significant with a P-value of ${ }^{\mathrm{m}} 0.561$ for the FT and ${ }^{\mathrm{n}} 0.337$ for the SS method by the Mann-Whitney test. Between the local FT and the general SS, ${ }^{\circ}$ the mean value of PreMRD, was not statistically significant statistically (0.415) by the Mann-Whitney test. However, the mean values of PostMRD 1 and DiffMRD 1 were statistically significant with P-values of 0.000 and 0.016 , respectively, by the Mann-Whitney

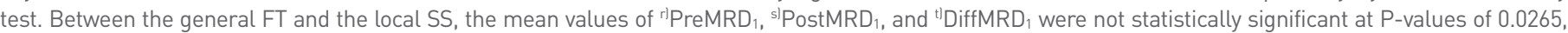
0.080 , and 0.774 , respectively, by independent sample t-tests. ${ }^{u}$ The difference of the mean PreMRD 1 among the four groups was not significant statistically with a P-value of 0.162 by the Kruskal-Wallis independent test. The values $(a, b, c, d, g, h, k, l, p$, and q) indicate statistical significance.

FT, frontalis transfer; SS, silicone sling; $\mathrm{MRD}_{1}$, marginal reflex distance 1 ; Pre-, preoperative; Post-, postoperative; DiffMRD ${ }_{1}, \mathrm{PostMRD}_{1}-\mathrm{PreMRD}_{1}$.
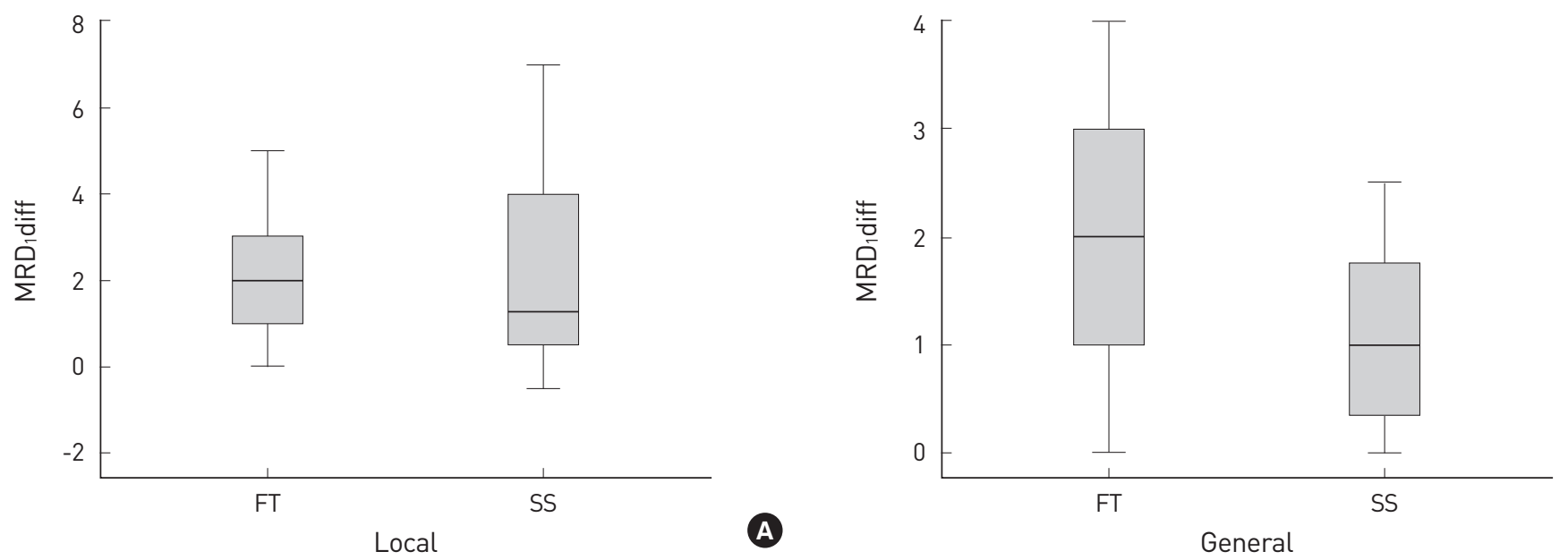

B

Fig. 3. Graphs showing the relationship between the frontalis transfer and the silicone sling (SS) methods with regard to the mean values of DiffMRD 1 between postoperative and preoperative MRD ${ }_{1}$. (A) Under local anesthesia, the difference of the mean value between the frontalis transfer (local FT, $n=53,2.04 \pm 1.224 \mathrm{~mm}$ ) and the SS method (local SS, $n=22,2.01 \pm 1.963 \mathrm{~mm}$ ) was not statistically significant with $\mathrm{P}=0.430$ by the Mann-Whitney test. (B) However, under general anesthesia, the difference of the mean value between the frontalis transfer lgeneral FT, $\mathrm{n}=18,2.17 \pm 1.339 \mathrm{~mm}$ ) and the SS method (general SS, $\mathrm{n}=11,1.11 \pm 0.848 \mathrm{~mm}$ ) was statistically significant with $\mathrm{P}=0.015$ by an independent sample t-test. It was shown that general FT, local FT, and local SS groups had an MRD, difference of approximately $2 \mathrm{~mm}$ or more.

ptosis and determine the degree of correction under local anesthesia. However, hematoma can be caused by muscle contraction and pain under local anesthesia (Table 4). Nevertheless, because some patients had extreme anxiety about the surgery or were too young to be cooperative, they were given general anesthesia.

In a previous study, postoperative ptosis showed no relationship 
Table 4. Early and late post-surgical complications

\begin{tabular}{|c|c|c|c|c|}
\hline & \multicolumn{2}{|c|}{ Frontalis transfer } & \multicolumn{2}{|c|}{ Silicone rod suspension } \\
\hline & $\begin{array}{c}\text { Local FT } \\
5 \text { cases }(9.4 \%)\end{array}$ & $\begin{array}{c}\text { General FT } \\
0 \text { case }\end{array}$ & $\begin{array}{c}\text { General SS } \\
1 \text { case }(9.1 \%)\end{array}$ & $\begin{array}{c}\text { Local SS } \\
3 \text { cases }(13.6 \%)\end{array}$ \\
\hline Complications & Postoperative bleeding, both sides & & Recurrence, one side & Undercorrection, both sides \\
\hline Revision time & The operative day & & 7 days later & 13 days post surgery \\
\hline \multirow[t]{14}{*}{ Revision operation } & Bleeding control & & Rod adjustment under local anesthesia & $\mathrm{FT}$ \\
\hline & Undercorrection, one side & & & Fold disappearance, one side \\
\hline & 9 months later & & & 5 months later \\
\hline & FT & & & Skin-to-tarsal fixation \\
\hline & Fold disappearance, both sides & & & Recurrence, one side \\
\hline & 12 months later & & & 7 months later \\
\hline & Skin-to-tarsal & & & Rod adjustment \\
\hline & Fixation & & & \\
\hline & Recurrence, one side & & & \\
\hline & 13 months later & & & \\
\hline & FT & & & \\
\hline & Recurrence, one side & & & \\
\hline & 13 months later & & & \\
\hline & SS under local anesthesia & & & \\
\hline
\end{tabular}

FT, frontalis transfer; SS, silicone sling.

to preoperative ptosis severity, similar to the results of our data in most groups in this study [13]. However, FT performed under local anesthesia was positively correlated with PostMRD ${ }_{1}$, and weakly positive correlated with $\mathrm{DiffMRD}_{1}$ and PreMRD $\mathrm{P}_{1}$ (Fig. 2). A coefficient of $21.3 \%$ was found in the statistical causal relationship between PreMRD $\mathrm{P}_{1}$ and PostMRD $\mathrm{D}_{1}$ as observed from the following: PostMRD $_{1}=2.041+0.235 \times\left(\right.$ PreMRD $\left._{1}\right)$ in the local FT group as determined by linear regression analysis $(\mathrm{P}=0.000$ in one-way $\mathrm{AN}$ OVA), unlike other groups of our institute.

Few studies have mentioned the results of blepharoptosis after surgery under different anesthetic conditions, and the present study showed that both the general FT and local FT groups showed an average 2-mm $\mathrm{MRD}_{1}$ increase, and the general SS group showed an average $1-\mathrm{mm} \mathrm{MRD}_{1}$ increase. The mean $\mathrm{MRD}_{1}$ differences in the local FT and general SS groups were $2.04 \pm 1.224 \mathrm{~mm}$ and 1.11 $\pm 0.848 \mathrm{~mm}$, respectively, and the $\mathrm{MRD}_{1}$ difference in the general FT $(2.17 \pm 1.339 \mathrm{~mm})$ and general SS $(1.11 \pm 0.848 \mathrm{~mm})$ groups were statistically significant (Table 3 ). The mean $\mathrm{MRD}_{1}$ difference in the local SS group was not significant from those in the other three groups, and the PreMRD 1 and PostMRD 1 values in the local SS group were significantly different from those in the local FT group. Therefore, the calculated $\mathrm{MRD}_{1}$ difference $(2.01 \pm 1.921$ $\mathrm{mm}$ ) in the local SS group was expected to be similar to the $\mathrm{MRD}_{1}$ difference in the local FT and general FT groups. In other words, the general FT, local FT, and local SS groups had an average of 2 mm or greater $\mathrm{MRD}_{1}$ increase. Specifically, the local FT group had

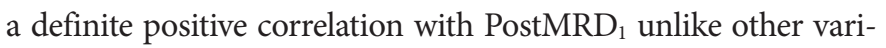
ables. The group under local anesthesia had a weak correlation with PostMRD $_{1}$, and the group under general anesthesia had no correlation with PostMRD .

From the intergroup analysis ( $\mathrm{P}=0.032$ by ANOVA) of the eight age groups with regard to $\mathrm{MRD}_{1}$ differences, the difference was higher for the age group of 61 to 70 years, followed by 41 to 50,11 to 20 , and 0 to 10 years. Further, in this study, most of the patients in the general SS groups were 10 years or younger, and these differences were thought to result from children's inadequate frontalis muscle contraction [20]. From this study, we believe a higher target tension level of the SS should be employed during surgery under general anesthesia compared to local anesthesia. Under general anesthesia, FT results in few complications and revision surgeries. Silicone rods are readily available and the tension can be adjusted in a relatively easier manner even under postoperative conditions. Further, even if the $\mathrm{MRD}_{1}$ increase after general SS is relatively small, the frontalis suspension sling surgery using silicon rods seems to be a better option under local anesthesia; however, this procedure may be associated with recurrence (Table 4). In the future, a prospective study is needed to determine the optimal increase in target tension level needed for improved effectiveness of the procedure under general anesthesia, because an increase in silicone tension could cause a longer period with incomplete eyelid closure during sleep and lagophthalmos in the downward gaze [13].

\section{REFERENCES}

1. Song R, Song Y. Treatment of blepharoptosis. Direct transplantation of the frontalis muscle to the upper eyelid. Clin Plast Surg 1982;9:45-8.

2. Zhou M, Jin R, Li Q, et al. Frontalis muscle flap advancement for correction of severe ptosis under general anesthesia: modified surgical 
design with 162 cases in China. Aesthetic Plast Surg 2014;38:503-9.

3. Lai CS, Chang KP, Lee SS, et al. The role of frontalis orbicularis oculi muscle flap for correction of blepharoptosis with poor levator function. Ann Plast Surg 2013;71 Suppl 1:S29-36.

4. Medel R, Vasquez L, Wolley Dod C. Early frontalis flap surgery as first option to correct congenital ptosis with poor levator function. Orbit 2014;33:164-8.

5. Zou C, Wang JQ, Guo X, et al. Long-term histopathologic study of the frontalis muscle flap after frontalis suspension for severe ptosis repair. Ophthal Plast Reconstr Surg 2013;29:486-91.

6. Vasquez LM, Alonso T, Medel R. Direct frontalis flap with and without levator pulley for correction of severe ptosis with poor levator function in the same patient. Orbit 2012;31:102-6.

7. Park DD, Ramadhan A, Han DG, et al. Comparison of Blepharoptosis Correction Using Muller-aponeurosis Composite Flap Advancement and Frontalis Muscle Transfer. Plast Reconstr Surg Glob Open 2014; 2:e200.

8. Lee MJ, Oh JY, Choung HK, et al. Frontalis sling operation using silicone rod compared with preserved fascia lata for congenital ptosis a three-year follow-up study. Ophthalmology 2009;116:123-9.

9. Bernardini FP, de Conciliis C, Devoto MH. Frontalis suspension sling using a silicone rod in patients affected by myogenic blepharoptosis. Orbit 2002;21:195-8.

10. Park DH, Choi WS, Yoon SH, et al. Comparison of levator resection and frontalis muscle transfer in the treatment of severe blepharoptosis. Ann Plast Surg 2007;59:388-92.
11. Jordan DR, Anderson RL. The aponeurotic approach to congenital ptosis. Ophthalmic Surg 1990;21:237-44.

12. Fox SA. Complications of frontalis sling surgery. Am J Ophthalmol 1967;63:758-62.

13. Liu HP, Shao Y, Li B, et al. Frontalis muscle transfer technique for correction of severe congenital blepharoptosis in Chinese patients: an analysis of surgical outcomes related to frontalis muscle function. J Plast Reconstr Aesthet Surg 2015;68:1667-74.

14. Ben Simon GJ, Macedo AA, Schwarcz RM, et al. Frontalis suspension for upper eyelid ptosis: evaluation of different surgical designs and suture material. Am J Ophthalmol 2005;140:877-85.

15. Wasserman BN, Sprunger DT, Helveston EM. Comparison of materials used in frontalis suspension. Arch Ophthalmol 2001;119:687-91.

16. Wagner RS. Comparing suture materials used in frontalis suspension procedures. J Pediatr Ophthalmol Strabismus 2015;52:76.

17. Ramirez OM, Peña G. Frontalis muscle advancement: a dynamic structure for the treatment of severe congenital eyelid ptosis. Plast Reconstr Surg 2004;113:1841-51.

18. Crawford JS. Repair of ptosis using frontalis muscle and fascia lata: a 20-year review. Ophthalmic Surg 1977;8:31-40.

19. Etezad Razavi M, Khalifeh M, Yazdani A. Comparing open and closed techniques of frontalis suspension with silicone rod for the treatment congenital blepharoptosis. Orbit 2014;33:91-5.

20. Morris CL, Buckley EG, Enyedi LB, et al. Safety and efficacy of silicone rod frontalis suspension surgery for childhood ptosis repair. J Pediatr Ophthalmol Strabismus 2008;45:280-90. 